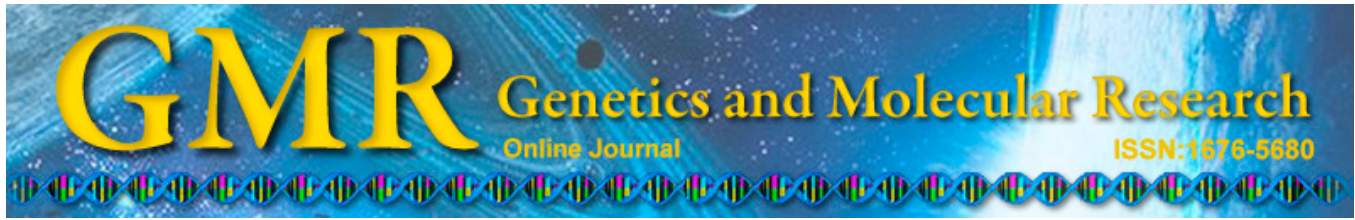

\title{
Effect of morphine preconditioning in the delayed phase on the expression of p38 mitogen-activated protein kinase in a rabbit model of myocardial ischemia-reperfusion injury
}

\author{
K. Ran ${ }^{1}$, Z.X. Gong ${ }^{1}$, D.L. Yang ${ }^{1}$, Y.T. Chang ${ }^{1}$, K.M. Duan ${ }^{2}$ and Y.W. Ou ${ }^{2}$ \\ ${ }^{1}$ Department of Anesthesiology, The Second Xiangya Hospital, \\ Central South University, Changsha, China \\ ${ }^{2}$ Department of Anesthesiology, The Third Xiangya Hospital, \\ Central South University, Changsha, China \\ Corresponding author: D.L. Yang \\ E-mail: 1070317330@qq.com
}

Genet. Mol. Res. 14 (2): 6642-6648 (2015)

Received June 3, 2014

Accepted January 23, 2015

Published June 18, 2015

DOI http://dx.doi.org/10.4238/2015.June.18.7

ABSTRACT. This study aimed to investigate the protective effects of
delayed morphine preconditioning on myocardial ischemia-reperfusion
injury. We randomly divided 30 rabbits into three groups with $10 \mathrm{rab}-$
bits in each group as follows: sham operation group (C group), isch-
emia-reperfusion group (I/R group), and morphine pretreatment group
(M group). Rabbits in $\mathrm{C}$ Group received left coronary without blocking
for $160 \mathrm{~min}$. The left descending artery of rabbits in the I/R group was
blocked for 40 min and reperfused for $120 \mathrm{~min}$. Rabbits in the $\mathrm{M}$ group
received intravenous administration of $1.0 \mathrm{mg} / \mathrm{kg}$ morphine; after $24 \mathrm{~h}$,
rabbits in this group received the same treatment as that administered
to the I/R group. We determined tumor necrosis factor alpha (TNF- $\alpha$ )
levels in blood samples from the internal carotid artery of rabbits in 
each group $20 \mathrm{~min}$ before occlusion of the left descending coronary artery, 20 and 40 min after occlusion of the left descending coronary artery, and 1 and $2 \mathrm{~h}$ after myocardial reperfusion. After $120 \mathrm{~min}$ of reperfusion, immunoblotting was used to measure the activity levels of myocardial p38 mitogen-activated protein kinase (MAPK); in addition, the infarct size was measured. Compared to the $\mathrm{I} / \mathrm{R}$ group, the $\mathrm{M}$ group showed a significant decrease in TNF- $\alpha$ levels, p38 MAPK activity, and the myocardial infarct size (I/R group $37.8 \% \pm 1.7 \%$ vs $21.5 \% \pm 2.4 \%$; $\mathrm{P}<0.05)$. Thus, morphine preconditioning in the delayed phase may exert protective effects on myocardial I/R injury by inhibiting myocardial p38 MAPK activity and decreasing TNF- $\alpha$ production.

Key words: Morphine; Myocardial ischemia-reperfusion injury; Delayed preconditioning; p38 Mitogen-activated protein kinase

\section{INTRODUCTION}

The protective effect of ischemic preconditioning on the myocardium has been confirmed in a previous study (Zhu et al., 2008). A recent study has shown that morphine pretreatment induces a delayed protective effect on the myocardium (Jiang et al., 2006), but the mechanism underlying this effect has not been clarified thus far. p38 Mitogen-activated protein kinase (p38 MAPK) is an intracellular signal transduction enzyme, and inhibiting the activity of p38 MAPK decreases the degree of myocardial injury (Li et al., 2008). Whether the protective effects of morphine preconditioning in the delayed phase are associated with p38 MAPK have not been clarified to date; therefore, in this study, we determined the effect of morphine pretreatment on the activity of p38 MAPK in myocardial cells to clarify the protective effects of morphine in ischemia-reperfusion (I/R) injury.

\section{MATERIAL AND METHODS}

\section{Materials}

\section{Animals}

Thirty healthy adult male New Zealand white rabbits weighing 2.0-2.5 kg were provided by the Animal Department of Xiangya Medical College.

\section{Reagents}

p38 MAPK antibody (Anti-ATF-2) was purchased from Calbiochem (USA). Evans blue, nitroblue tetrazolium chloride (TTC), sodium pentobarbital, and acrylamide were purchased from Sigma (USA). Horseradish peroxidase (HRPO)-labeled goat anti-rabbit immunoglobulin $\mathrm{G}$ (IgG; $1.0 \mathrm{mg} / \mathrm{mL}$ ), tumor necrosis factor alpha (TNF- $\alpha$ ) enzyme-linked immunosorbent assay (ELISA) kit was purchased from Jingmei (Shenzhen). Anhydrous ethanol, isopropyl alcohol, chloroform, xylene, agarose, and Tris were purchased from a domestic reagent company. 


\section{Methods}

\section{Preparation of an I/R model}

A rabbit model of $\mathrm{I} / \mathrm{R}$ injury was prepared according to the method described previously (Ran, 2008a,b).

\section{Animal grouping}

We randomly divided 30 rabbits into three groups with 10 rabbits in each group as follows: sham operation group (C group), I/R group, and morphine pretreatment group (M group). Rabbits in the $\mathrm{C}$ group received intravenous administration of $1.0 \mathrm{~mL} / \mathrm{kg}$ normal saline (NS); after $24 \mathrm{~h}$, the left coronary was lined without blocking for $160 \mathrm{~min}$. Rabbits in the $\mathrm{I} / \mathrm{R}$ group received intravenous administration of $1.0 \mathrm{~mL} / \mathrm{kg} \mathrm{NS}$; after $24 \mathrm{~h}$, the left descending artery was occluded for $40 \mathrm{~min}$ and reperfused for $120 \mathrm{~min}$. Rabbits in the $\mathrm{M}$ group received intravenous administration of $1.0 \mathrm{mg} / \mathrm{kg}$ morphine; after $24 \mathrm{~h}$, rabbits in this group received the same treatment as that given to the rabbits in the I/R group.

\section{Determination of TNF- $\alpha$ levels}

We measured the TNF- $\alpha$ levels in the internal carotid arterial blood samples from rabbits in each group $20 \mathrm{~min}$ before occlusion of the left descending coronary artery (T1), 20 min after occlusion of the left descending coronary artery (T2), 40 min after occlusion of the left descending coronary artery (T3), $1 \mathrm{~h}$ after myocardial reperfusion (T4), and $2 \mathrm{~h}$ after myocardial reperfusion (T5) using sandwich ELISA.

\section{Measurement of the myocardial infarct size}

The coronary artery was blocked again $2 \mathrm{~h}$ after reperfusion, and $2 \mathrm{~mL} \mathrm{2 \%}$ Evans blue was injected in the internal carotid artery to stain the myocardium to differentiate between the ischemic (non-blue) and non-ischemic (blue) tissues. The hearts were quickly removed and horizontally cut into approximately 2-mm slices; the thin myocardial slices were dried using filter papers, the right ventricle and the non-ischemic tissue were cut off, and the quality of the tissue was determined. The slices of the ischemic myocardium were incubated with $0.5 \%$ TTC phosphate buffer, $\mathrm{pH} 7.4$, at $37^{\circ} \mathrm{C}$ for 15 min to determine the infarct tissues. We separated and measured the quality of the necrotic area (gray-white) and non-necrotic areas (dark red). Ischemia and the myocardial infarct size were calculated as a percentage of the total left ventricular mass.

\section{Pathological examination of the myocardial tissues}

After reperfusion, $1 \times 1 \times 1-m m$ apex myocardial tissues from each group were taken for examination of the ultrastructure using transmission electron microscopy.

\section{Western blot analysis of the myocardial tissue}

Myocardial proteins were extracted according to the method described by Wang 
(2005). The extracted myocardial proteins were stored at $-70^{\circ} \mathrm{C}$ for further analysis. We performed polyacrylamide gel electrophoresis with $12.5 \%$ sodium dodecyl sulfate using $100 \mu \mathrm{g}$ myocardial proteins. The isolated myocardial proteins were transferred to a polyvinylidine fluoride (PVDF) membrane using the Pharmacia Nova Blot power transfer device. The membrane was maintained in an isolated solution at room temperature for $3 \mathrm{~h}$. p38 MAPK antibody was added to the membrane, and the membrane was incubated overnight at $4^{\circ} \mathrm{C}$. Subsequently, the membranes were washed four times with TTBS buffer for $15 \mathrm{~min}$ and anti-goat anti-rabbit IgG was added; then, the membranes were shaken and incubated at room temperature for $1 \mathrm{~h}$. After washing with TTBS buffer thoroughly, we performed the enhanced chemiluminescence reaction. The PVDF membrane strips were scanned into a computer for image analysis to obtain the relative gray density values, which may represent the p38 MAPK activity levels.

\section{Statistical analysis}

SPSS13.0 statistical software was used for statistical analysis. Continuous variables are reported as means $\pm \mathrm{SD}$. One-way ANOVA and Newman-Keuls method were used for statistical analysis. A difference of $\mathrm{P}<0.05$ was considered to be statistically significant.

\section{RESULTS}

\section{Changes in the ultrastructure of the myocardium}

Examination under the electron microscope showed that the myocardial mitochondria in the sham operation group had normal morphology and abundant glycogen (Figure 1A). The myocardial mitochondria in the I/R group showed edema, severe vacuolization, and a fuzzy boundary (Figure 1B). The myocardial mitochondria in the M group showed mild swelling and decreased glycogen (Figure 1C).
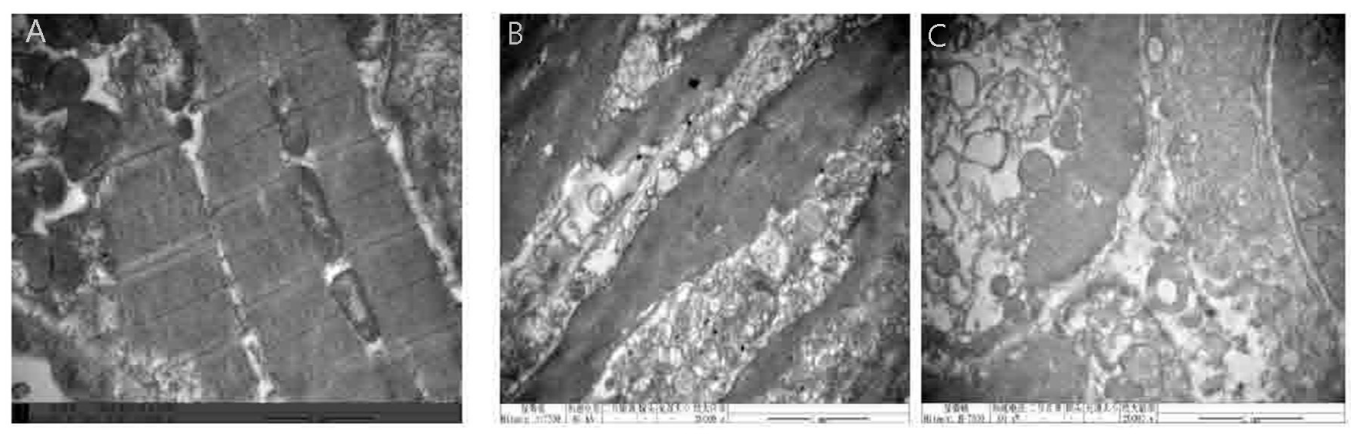

Figure 1. Myocardial cell morphological change in electron microscope (20,000X) A. sham-operation group; B. I/R group; C. morphine group.

\section{Serum TNF- $\alpha$ concentration changes}

Compared to the $\mathrm{C}$ group, the $\mathrm{I} / \mathrm{R}$ and $\mathrm{M}$ groups showed a significant increase in the 
serum TNF- $\alpha$ levels after I/R injury $(\mathrm{P}<0.05)$. However, compared to the $\mathrm{I} / \mathrm{R}$ group, the $\mathrm{M}$ group showed a significant decrease in the TNF- $\alpha$ levels $(\mathrm{P}<0.05$; Table 1).

Table 1. Serum TNF- $\alpha$ concentrations changes in each group (pg/mL, means $\pm \mathrm{SD})$.

\begin{tabular}{lcccccc}
\hline Group & $\mathrm{n}$ & $\mathrm{T} 1$ & $\mathrm{~T} 2$ & $\mathrm{~T} 3$ & $\mathrm{~T}$ & T5 \\
\hline C group & 10 & $52.3 \pm 6.7$ & $54.2 \pm 4.5$ & $53.7 \pm 3.1$ & $54.6 \pm 4.2$ & $51.5 \pm 5.6$ \\
I/Rgroup & 10 & $54.1 \pm 5.3$ & $78.6 \pm 6.4$ & $88.1 \pm 7.9^{*}$ & $110.5 \pm 9.4^{*}$ & $157.6 \pm 5.5^{*}$ \\
M group & 10 & $56.7 \pm 7.4$ & $61.3 \pm 5.6$ & $72.6 \pm 5.4^{*}$ & $91.8 \pm 6.9^{* \Delta}$ & $113.8 \pm 8.2^{* \Delta}$
\end{tabular}

*Compared with $\mathrm{C}$ group, $\mathrm{P}<0.05 ;{ }^{\triangle}$ compared with $\mathrm{I} / \mathrm{R}$ group, $\mathrm{P}<0.05$.

\section{Changes in the myocardial infarct size}

No significant difference was observed in the infarct size between the $\mathrm{I} / \mathrm{R}$ and $\mathrm{M}$ groups $(\mathrm{P}>0.05)$. The infarct size in the $\mathrm{M}$ group was significantly smaller than that in the $\mathrm{I} / \mathrm{R}$ group $(\mathrm{P}<0.05$; Table 2).

Table 2. Myocardial infarction size and ischemic area among groups (means $\pm \mathrm{SD}, \mathrm{N}=7$ ).

\begin{tabular}{lccccc}
\hline Group & LV $(\mathrm{g})$ & AAR $(\mathrm{g})$ & IS $(\mathrm{g})$ & AAR/LV $(\%)$ & IS/AAR $(\%)$ \\
\hline C group & $3.16 \pm 0.68$ & - & - & - & - \\
I/R group & $2.93 \pm 0.44$ & $0.88 \pm 0.35$ & $0.33 \pm 0.06$ & $33.6 \pm 3.1$ & $37.8 \pm 1.7$ \\
M group & $3.07 \pm 0.56$ & $1.09 \pm 0.29$ & $0.24 \pm 0.05$ & $35.4 \pm 2.6^{*}$ & $21.5 \pm 2.4^{\Delta}$ \\
\hline
\end{tabular}

*Compared with $\mathrm{C}$ group, $\mathrm{P}<0.05 ;{ }^{\Delta}$ compared with $\mathrm{I} / \mathrm{R}$ group, $\mathrm{P}<0.05 . \mathrm{LV}=$ left venticular; $\mathrm{AAR}=$ ischemic myocardial; IS = infarction myocardial.

\section{Effect of morphine preconditioning in the delayed phase on myocardial p38 MAPK activity}

The myocardial p38 MAPK activity in the C Group was significantly lower than that in the I/R and $\mathrm{M}$ groups (gray values, $20.3 \pm 2.5 v s 67.4 \pm 3.1$ and $51.6 \pm 2.2 ; \mathrm{P}<0.05$ ). Moreover, the myocardial p38 MAPK protein activity in the M group was significantly lower than that in $\mathrm{I} / \mathrm{R}$ group $(\mathrm{P}<0.05$; Figure 2$)$.
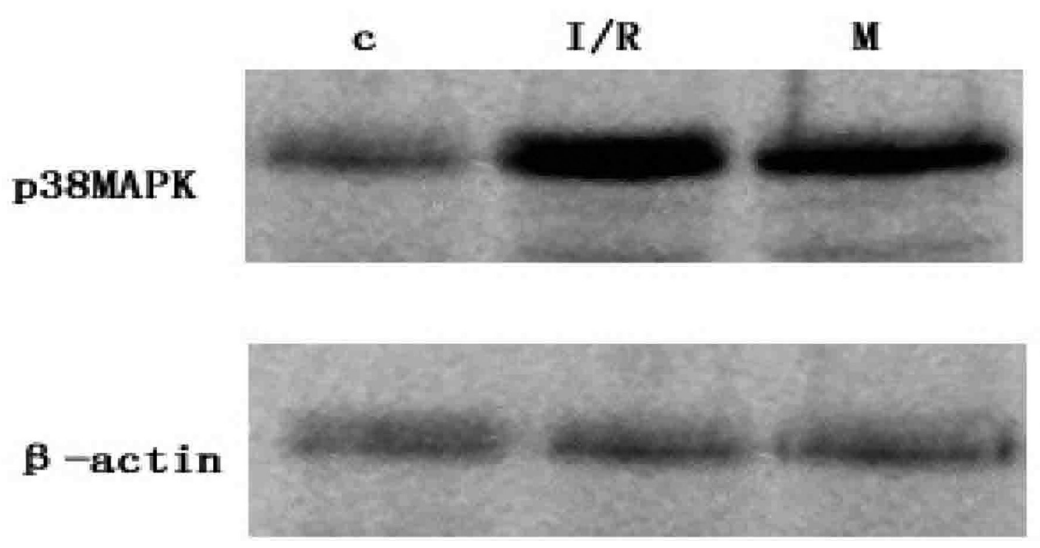

Figure 2. Myocardium p38MAPK protein activity expression in rabbits. 


\section{DISCUSSION}

p38 MAPK is a member of the intracellular signal transduction enzyme MAPK superfamily. p38 MAPK is the key signaling protein involved in the regulation of apoptosis. p38 MAPK is almost inactive in the resting state; however, under ischemic and hypoxic pathological stimuli, p38 MAPK in the myocardial cells is rapidly activated to induce stress-injury of myocardial cells. p38 MAPK-specific inhibitor SB203580 inhibits p38 MAPK activity, decreases myocardial apoptosis, and recovers the heart function and decreases the degree of myocardial injury (Li et al., 2006). In this study, p38 MAPK activity was the lowest in the myocardial cells of rabbits in the sham operation group, but upon induction of I/R injury, the p38 MAPK activity significantly increased in the myocardial cells of rabbits in the $\mathrm{I} / \mathrm{R}$ and $\mathrm{M}$ groups. Further, our results showed that the morphine preconditioning in the delayed phase may significantly inhibit the myocardial p38 MAPK activity and simultaneously improve the ultrastructure of the ischemic myocardium and decrease the myocardial infarct size in the $\mathrm{I} / \mathrm{R}$ group, which suggests that morphine may decrease the myocardial I/R injury and induce a delayed protective effect through inhibition of p38 MAPK activity. Previous studies have suggested that one of the mechanisms underlying $\mathrm{I} / \mathrm{R}$ injury is an excessive inflammatory response with TNF- $\alpha$ as a major pro-inflammatory factor. TNF- $\alpha$ can activate neutrophils and endothelial cells, increase cell aggregation and expression of adhesion molecules in the ischemic area, cause cytokine cascade, promote the release of oxygen free radicals and proteolytic enzymes to induce membrane damage and cell autolysis, which ultimately results in myocardial injury, and thus, TNF- $\alpha$ is a key factor in the chain reaction of I/R injury (Frangogiannis et al., 2002; McEvoy et al., 2009). A significant increase in the release of TNF- $\alpha$ in the I/R group observed in our study was consistent with that reported in the previous studies. The release of TNF- $\alpha$ decreased in the M group, which suggested that morphine preconditioninginduced delayed protective effect on the myocardium was associated with a decrease in the release of TNF- $\alpha$ in the myocardium. The mechanism underlying the release of TNF- $\alpha$ in the myocardium during $\mathrm{I} / \mathrm{R}$ has not been clarified thus far; previous studies have shown that the p38 MAPK inhibitor SB203580 decreases the release of TNF- $\alpha$ (Kimura et al., 2006), which indicates that morphine preconditioning in the delayed phase may decrease the release of TNF- $\alpha$ in the myocardium by inhibiting the activation of p38 MAPK.

In summary, morphine preconditioning in the delayed phase may inhibit myocardial p38 MAPK activity, and thus, decrease the release of the proinflammatory cytokine TNF- $\alpha$ and inhibit the inflammatory response; this may be one of the molecular mechanisms underlying the delayed protective effect on the myocardium.

\section{ACKNOWLEDGMENTS}

Research supported by the Changsha Technology Bureau Proj. (\#K1003049-31).

\section{REFERENCES}

Frangogiannis NG, Smith CW and Entman ML (2002). The inflammatory response in myocardial infarction. Cardiovasc. Res. 53: 31-47.

Jiang X, Shi E, Nakajima Y and Sato S (2006). COX-2 mediates morphine-induced delayed cardioprotection via an iNOSdependent mechanism. Life Sci. 78: 2543-2549.

Kimura H, Shintani-Ishida K, Nakajima M, Liu S, et al. (2006). Ischemic preconditioning or p38 MAP kinase inhibition 
attenuates myocardial TNF alpha production and mitochondria damage in brief myocardial ischemia. Life Sci. 78: 1901-1910.

Li J, Lang MJ, Mao XB, Tian L, et al. (2008). Antiapoptosis and mitochondrial effect of pioglitazone preconditioning in the ischemic/reperfused heart of rat. Cardiovasc. Drugs Ther. 22: 283-291.

Li Z, Ma JY, Kerr I, Chakravarty S, et al. (2006). Selective inhibition of p38alpha MAPK improves cardiac function and reduces myocardial apoptosis in rat model of myocardial injury. Am. J. Physiol. Heart Circ. Physiol. 291: H19721977.

McEvoy MD, Sabbagh MJ, Taylor AG, Zavadzkas JA, et al. (2009). Aprotinin modifies left ventricular contractility and cytokine release after ischemia-reperfusion in a dose-dependent manner in a murine model. Anesth. Analg. 108: 399-406.

Ran K, Duan KM, Zou DQ, Zhu R. et al. (2008a). Isoflurane delayed preconditioning on rabbit myocardial ischemiareperfusion damage nuclear factor-kappa B. Zhonghua Jizhen Yixue Za Zhi 17: 834-837.

Ran K, Duan KM, Zou DQ, Li ZJ, et al. (2008b). Effect of isoflurane delayed preconditioning on myocardial ischemia reperfusion injury in rabbits. Zhong Nan Da Xue Xue Bao Yi Xue Ban 33: 146-150.

Wang M, Tsai BM, Turrentine MW, Mahomed Y, et al. (2005). p38 mitogen activated protein kinase mediates both death signaling and functional depression in the heart. Ann. Thorac. Surg. 80: 2235-2241.

Zhu X, Shen ZY, Zhong N, Zhang ZM (2008). The endogenous cyclooxygenase 2 in immature myocardial ischemia delayed preconditioning protection of the mitochondrial permeability transition pore. Suzhou Univ. J. 28: 367-370. 